Sharif University of Technology
Scientia Iranica
Transactions A: Civil Engineering
IRAN IENTIA $\quad$\begin{tabular}{l} 
http:/scientiairanica.sharif.edu \\
\hline
\end{tabular}

\title{
Numerical investigation of cover plate in RCS connections
}

\author{
N.K.A. Attari ${ }^{a}, *$ N. Azadvar ${ }^{b}$, and S. Alizadeh ${ }^{c}$ \\ a. Department of Structural Engineering, Building \& Housing Research Center, Tehran, P.O. Box 13145-1696, Iran. \\ b. Department of Civil Engineering, West Tehran Branch, Islamic Azad University, Tehran, Iran. \\ c. Department of Civil and Natural Resources Engineering, University of Canterbury, New Zealand.
}

Received 4 January 2017; received in revised form 22 August 2017; accepted 9 June 2018

\author{
KEYWORDS \\ RCS connections; \\ Composite structural \\ frames; \\ Finite element \\ method; \\ Cover plate; \\ Steel doubler plate.
}

\begin{abstract}
Due to the growing popularity of Reinforced Concrete column with Steel beam (RCS) moment frame system in recent years, there are a great number of publications about the performance of this structural system. In this study, 15 RCS joints with practical details were investigated using a verified finite element method. Joint details of the models included cover plate, additional bearing plate, Steel Doubler Plate (SDP), and joint stirrups. The results showed that Cover Plate (CP) could be used instead of the combination of SDP and joint stirrups; it improved the joint performance by increasing the confinement of joint region and contributing to joint shear strength.
\end{abstract}

2020 Sharif University of Technology. All rights reserved.

\section{Introduction}

Since the late 70's, composite structural frames consisting of steel and reinforced concrete have gained evergrowing popularity in building construction. One type of these structural systems is called RCS (Reinforced Concrete column Steel beam) moment frame [1]. The RCS moment frames became common in the United States and Japan in the late 1970's and early 1980's. Replacing the heavy wide-flange columns of a typical steel moment frame structure with the most costeffective reinforced concrete columns to resist the high axial compressive loads brings about economic superiority of the RCS system. Moreover, using this system has many other advantages; for instance, concrete columns are more fire resistant, the energy dissipation

\footnotetext{
*. Corresponding author. Tel.: +98 21 882-4126\%;

Fax: +9821 882-41267

E-mail addresses: n.attari@bhrc.ac.ir (N.K.A. Attari);

Azadvar.narges@wtiau.ac.ir (N. Azadvar);

Saeid.Alizadeh@pg.Canterbury.ac.nz (S.Alizadeh)
}

capacity of steel beams is higher than that of concrete beams, and the stiffness of concrete columns is greater than that of steel columns.

Several experimental programs have already been conducted for studying the performance of RCS connections. Bugeja [2] tested five interior and one exterior beam-column-slab subassemblies subjected to cyclic loading in two principal directions at Texas A\&M University. The specimens consisted of steel beams passing through the reinforced concrete columns in two orthogonal directions. The joint details included Face Bearing Plates (FBPs), erection steel columns, steel Cover Plates (CPs), and Steel Band Plates (SBPs). The composite beams were typically composed of steel beams mechanically connected to the RC slab using shear studs. The results indicated that the composite RCS beam-column-slab subassembly had excellent inelastic behavior and energy dissipation capacity under cyclic loading.

The problem of partial interaction in steelconcrete composite beams connected by flexible stud shear connectors was discussed by Machelski and Toczkiewicz [3]. In this research, the problem was 
formulated according to the modified Trost's theory of concrete ageing and the effects of parameter characterizing flexibility of the connection as well as the authors' own coefficients on the distribution of internal forces were illustrated. However, the phenomenon was not thoroughly formulated and described.

Eghbali and Mirghaderi [4] presented a beam to column connection with enhanced performance. In the current paper, two interior connections on a scale of $3 / 4$ were evaluated experimentally under cyclic lateral loading and a constant axial load on the column. In these specimens, the beams were connected to a vertical plate passing through the concrete column (through plate). Steel CPs eliminated any separation potential of the rigid shear connectors from the concrete while increasing the concrete strength. The through plate involved with concrete provided a strong panel zone with elastic behavior, and the proposed connection was a fully restrained one; moreover, the tested specimens provided permanent hysteretic diagrams without any pinching.

Nguyen et al. [5] studied the seismic performance of a new type of exterior RCS connections, in which a steel profile embedded inside RC column was directly welded to the steel beam. A full-scale exterior hybrid joint was built and tested under reversed cyclic loading without compressive axial force. The test results indicated that after yielding, the strength of the specimen continued to increase by approximately $20 \%$. The test specimen performed in a ductile manner with a ductility factor of $\mu=2.2$. This led to the conclusion that the RCS joint might be used as dissipative element in the structure of Ductility Class Medium (DCM).

Mirghaderi et al. [6] suggested a new moment in which two parallel beams passed through both sides of the column and were welded to the CPs surrounding the concrete column in the joint area. This provided some advantages over the previous constructions. One of them was that both the beam and the column were continuous in the joint area, which led to more reliable performance. The proposed connection was studied in two experimental tests under cyclic loading. The test results indicated that both specimens sustained $8 \%$ story drift with stable hysteretic loops and that the suggested connection was acceptable as a special moment connection. In addition, the test results demonstrated that the proposed design relationships were set properly such that the cover plates were maintained in the elastic phase. However, slight cracks appeared in the column and plastic hinges were formed in the beams in the vicinity of the column.

Hongtuo Qi et al. [7] conducted experimental and analytical studies on the behavior of tubed Steel Reinforced Concrete (SRC) stub columns subjected to axial compressive load. In this study, 25 tubed SRC stub columns were tested to investigate the failure mode and behavior of tubed SRC columns under axial load. The results indicated that tubed SRC stub columns had higher axial load capacity than usual SRC columns with the same volumetric steel ratio. Some equations were also proposed to predict the axial load strength of tubed SRC stub columns based on the experimental results.

A series of tests was performed on some ConcreteFilled Double-Skin Tubular (CFDST) columns with external steel rings by Ho and Dong [8]. The results showed that elastic strength, elastic stiffness, and ductility were increased by utilizing the steel rings as external confinement. In addition, a theoretical model was proposed to predict the axial strength of confined CFDST columns.

Wróblewski et al. [9] made estimations of shearing and axial stiffness of connecting elements and presented a substitute longitudinal modulus of elasticity of the reinforced concrete slab based on the results of experimental research. The analyses demonstrated that increasing the shearing stiffness of connection increased all the analyzed frequencies of flexural vibrations.

Cai et al. [10] numerically investigated the mechanical behavior and failure mechanism of SteelReinforced Concrete-Filled Steel Tubular (SRCFST) to examine the effects of steel tube ratio $(t \alpha)$, section steel ratio $(s \alpha)$, etc. on the mechanical behavior and ultimate resistance of the SRCFST columns under axial compression. The calculation results illustrated that peak strength and initial stiffness of CFST columns increased with increase in all parameters.

Alizadeh et al. [11] investigated the cyclic behavior of RCS connections. In their paper, two interior connections were tested under reversed cyclic loading. One of the specimens had a new proposed joint detail that consisted of additional bearing plates. Comparing the performance of two specimens showed that using additional bearing plates would increase bearing and shear strengths of the joint. Furthermore, a modified method for modeling of this type of connections was introduced using OpenSees software.

In another research conducted by Alizadeh et al. [12], some suggested joint details were simulated using verified Finite Element Model (FEM) model to investigate the performance of SBPs, FBPs, Wide Face Bearing Plates (WFBPs), ABPs, and Steel Doubler Plates (SDPs). The results indicated that the performance of the models directly depended on joint detailing, effectiveness of shear keys, and the amount of confinement placed on the joint region.

Some other research programs on RCS connections were conducted by other researchers such as Nguyen et al. [13], Men et al. [14], Chou and Chen [15], Shen [16], Zhang et al. [17], Li et al. [18], and Farahmand Azar [19]. Li et al. [20] reviewed some important researches in this field. 
There are many researches on the performance of RCS connections with different joint details; however, a small number of them focus on the behavior of the CPs in RCS joints. Thus, the performance of CPs and their effects on the joint shear stiffness and strength have not been well investigated. The aim of this study is to clarify the influence of SDPs and CPs on the performance of RCS connections. In this research program, a complete FEM study was conducted to investigate the performance of different types of joint details in combination with CP. The connections were simulated using ABAQUS [21] software and verified with the experimental results of Alizadeh et al. [12].

\section{Numerical modeling and verification}

The numerical models investigated in this paper were created based on a verified model by Alizadeh et al. [12]. A brief description of this experimental test is presented and the experimental test setup is shown in Figure 1. As observed in the figure, at the end points of the steel beams, the roller supports were used. The bottom end of the concrete column was pinned to strong floor. Two hydraulic jacks were used at the top of the column to impose reversed lateral cyclic loading. For the simulation, $300 \mathrm{kN}$ axial load was applied to the concrete column at the beginning of the test, which was about $4 \%$ of the gross axial strength of the column. The ends of beams and columns were braced laterally to prevent out-of-plane movements during the test.

The loading pattern consisted of 28 cycles beginning at $0.2 \%$ and maintaining $0.25 \%, 0.375 \%, 0.5 \%$, $0.75 \%, 1 \%, 1.5 \%, 2 \%, 3 \%, 4 \%, 5 \%$, and $6 \%$ drift angles, which were repeated in each cycle two times.

\subsection{Material properties}

The tested specimens were modeled by considering all the interactions, boundary conditions, and materials properties. Based on the experimental reports, ASTM A615 grade 75 [22] was utilized for longitudinal reinforcements and ASTM A615 grade 60 [22] was used for all transverse reinforcements. The steel beam materials were ASTM A572 grade 50 [23]. Based on the test results, the yield stress and ultimate strength of steel beam were $362.7 \mathrm{MPa}$ and $495 \mathrm{MPa}$, respectively. The material properties used in numerical simulation are shown in Table 1 and Figure 2. For reducing the computational costs, half of the models were simulated using the symmetrical situation at the center of the column. Since the end parts of the columns and beams did not experience significant nonlinear deformations, these regions were modeled using onedimensional beam elements as seen in Figure 3 .

The mean compressive strength of concrete was $50.8 \mathrm{MPa}$, which was modeled using the Concrete Dam-

Table 1. Material properties.

\begin{tabular}{ccc}
\hline & \multicolumn{2}{c}{$\begin{array}{c}\text { Steel beam and reinforcement } \\
\text { strength }\end{array}$} \\
\cline { 2 - 3 } & $\boldsymbol{F}_{\boldsymbol{y}}(\mathbf{M P a})$ & $\boldsymbol{F}_{\boldsymbol{u}}(\mathbf{M P a})$ \\
\hline Steel beam & 362.7 & 495 \\
$\Phi 10$ bar & 408 & 615 \\
$\Phi 18$ bar & 523 & 669 \\
\hline \multicolumn{3}{c}{ Concrete compression } \\
& \multicolumn{2}{c}{ strength $\left(\boldsymbol{f}_{\boldsymbol{c}}^{\prime}\right)$ (MPa) } \\
\hline Column & \multicolumn{2}{c}{50.8} \\
\hline \multicolumn{2}{c}{}
\end{tabular}

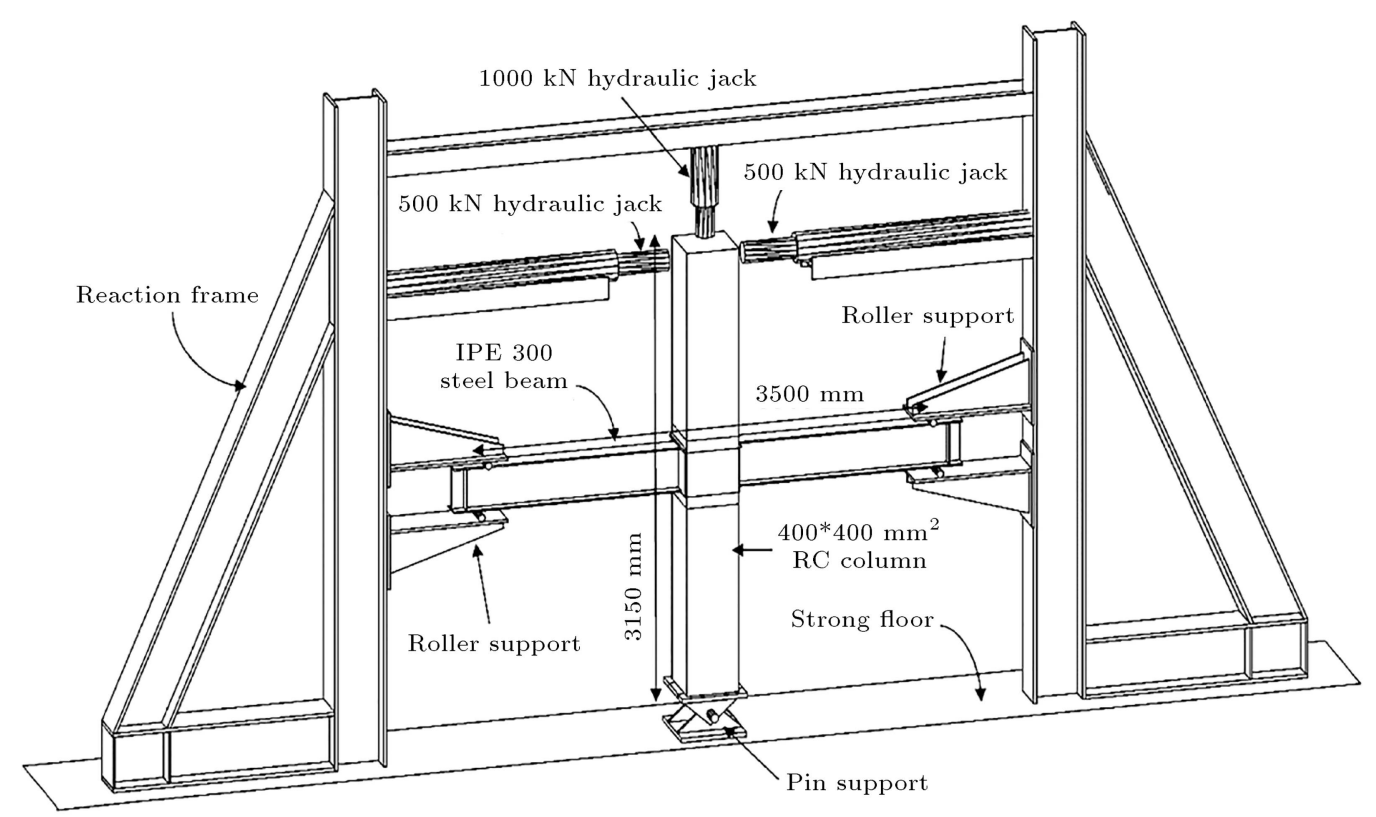

Figure 1. Test setup of experimental program. 


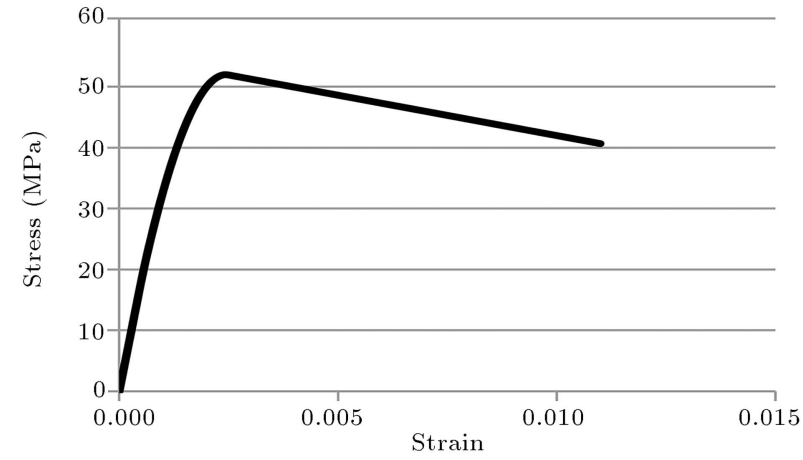

(a)

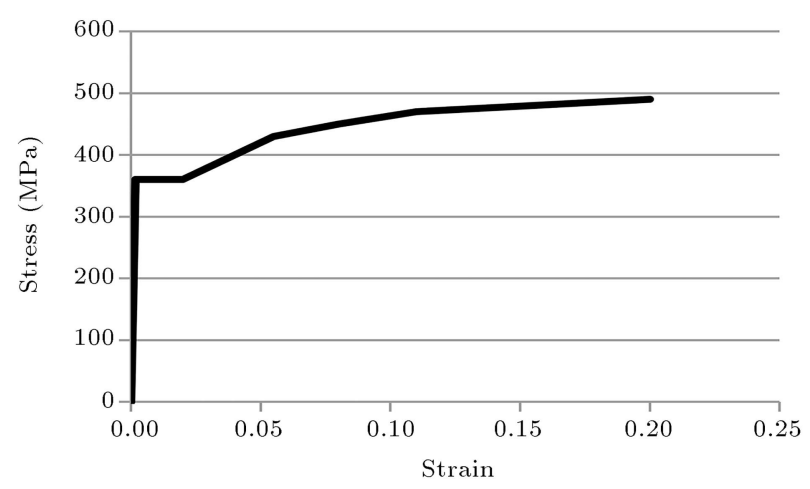

(b)

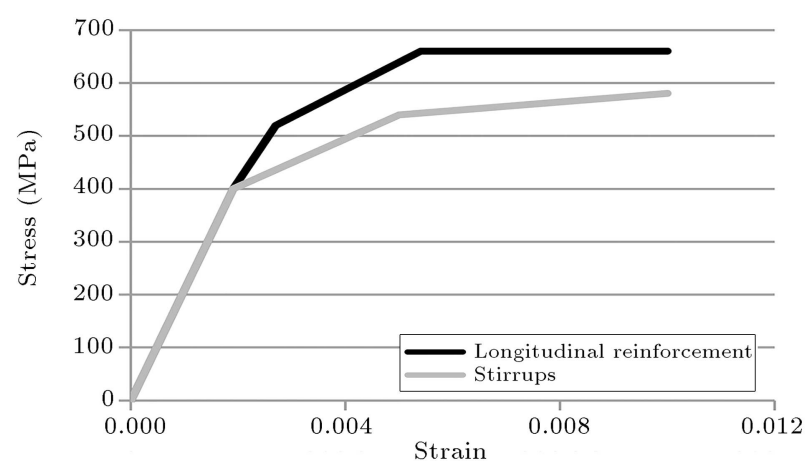

(c)

Figure 2. Material properties: (a) Concrete, (b) steel beam, and (c) reinforcement.

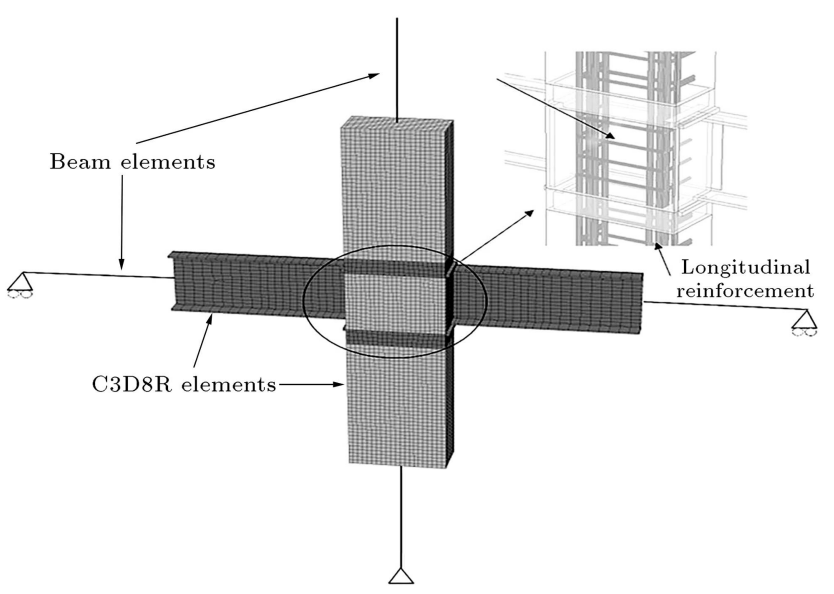

Figure 3. Finite Element Model (FEM). aged Plasticity model existing in ABAQUS library. This model is a continuum plasticity-based damage model for concrete and assumes that the two main failure mechanisms are tensile cracking and compressive crushing of the concrete material. The parameters required in this material model were obtained from CEB-FIP model code 90 [24] based on the concrete compressive strength. The compressive and tensile damage parameters were considered as linear functions of inelastic strains. The nonlinear behavior of steel beams and reinforcement bars was simulated using an isotropic hardening model based on the von Mises yield criterion. The stress-strain relationships of the steel beams were defined according to the results of uniaxial tension tests.

\subsection{Model specifications}

The 8-node solid elements, known as C3D8R elements in ABAQUS [21] software, were utilized for modeling steel beams and concrete columns. The reinforcements were modeled using one-dimensional two-node truss elements (T3D2) and they were fully embedded in concrete. These assumptions were used for simplifying the finite element models. Separation of steel beam and concrete column at the joint region was allowed during the analysis for better simulation of the interaction between the steel and concrete. The models were analyzed in two steps; first, the axial force of the column was applied and then, the column was pushed laterally up to $4 \%$ story drift.

The lateral load-story drift response of the verified model is presented in Figure 4. As it is shown, the simulated model shows very good agreement with the backbone curve of the tested specimen. The backbone curve is plotted based on ASCE41-13. Furthermore, as can be seen in Figure 5, the overall crack pattern of FEM model is very similar to the experimental results. It should be noted that since the numerical model is

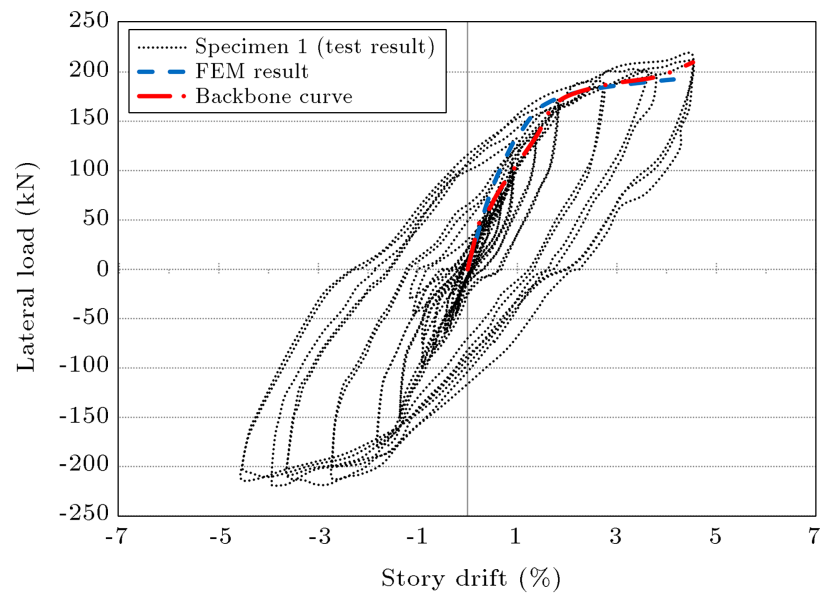

Figure 4. Test and Finite Element Model (FEM) lateral load-story drift responses. 

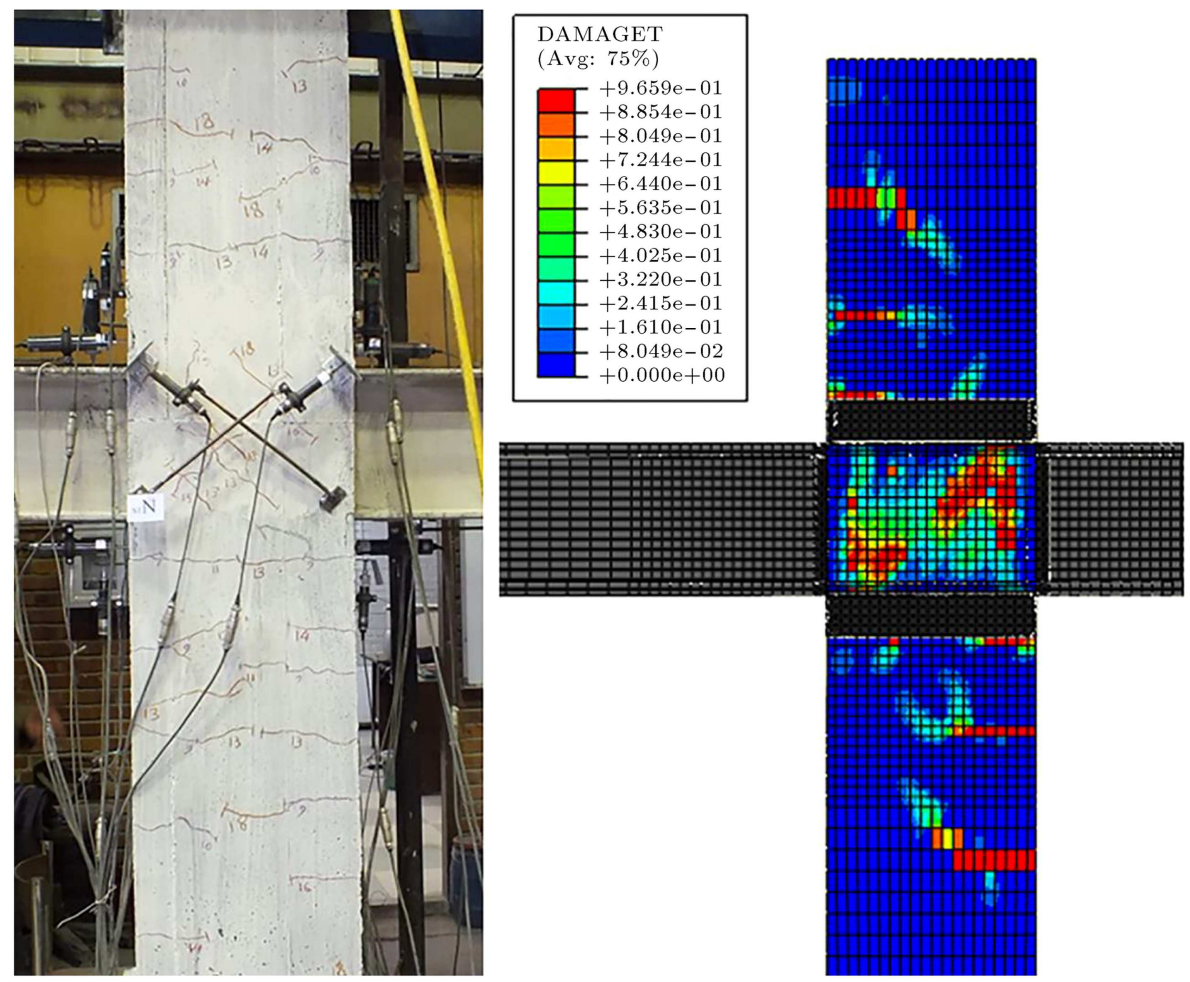

Figure 5. Test and Finite Element Model (FEM) crack patterns.

pushed monastically, the concrete cracks are formed at one side of the column.

\section{Case study}

\subsection{Simulated models}

Fifteen interior beam-through-type RCS connections are investigated numerically in this paper. Various joint details are simulated using the verified model to investigate the effects of $\mathrm{CP}, \mathrm{ABPs}$, and SDP on the behavior of RCS connections. Simulated models are grouped into three main categories to ensure that all the possible failure modes are captured. Each of these categories consists of models with and without CP and SDP.

All of the models consist of $3000 \mathrm{~mm}$ long concrete columns with $400 \times 400 \mathrm{~mm}^{2}$ square cross sections. Columns are reinforced with $16 \Phi 18$ steel bars. $\Phi 10$ bars are used for joint and column stirrups. IPE 300 steel sections with $3900 \mathrm{~mm}$ length are considered for the beams. In six models, the thickness of the flanges of the steel beams is increased to $20 \mathrm{~mm}$ for imposing larger forces on the panel zone. These models are specified by adding "(s)" to the end of the name of the model. In four models, the flanges of steel beams are increased to $25 \mathrm{~mm}$ and the diameter of the longitudinal reinforcements of the column is increased to $22 \mathrm{~mm}(\Phi 22)$ to close up the flexural capacity of steel beams and columns. These models are named by adding "(ss)" to the end of the name of the model.
In the joint regions of different models, L-shape stirrups, SDPs, SBPs, and CP are used based on Table 2. Figure 6 demonstrates typical joint details.

Model F-B-L-S is same as specimen 1 in the tests of Alizadeh et al. [12]. Model F-B-L-S (s) is similar to model F-B-L-S, while the flange thickness of the steel

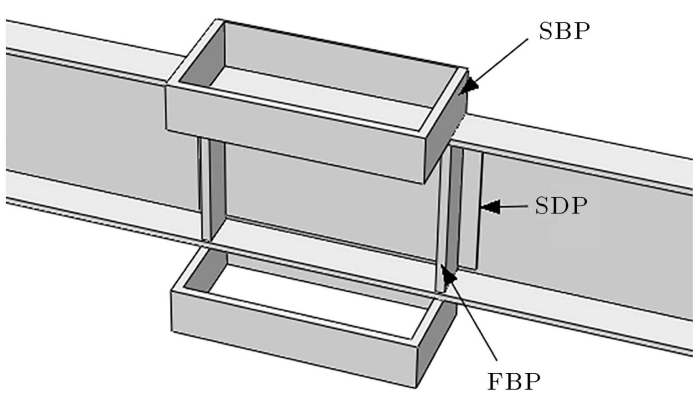

(a)

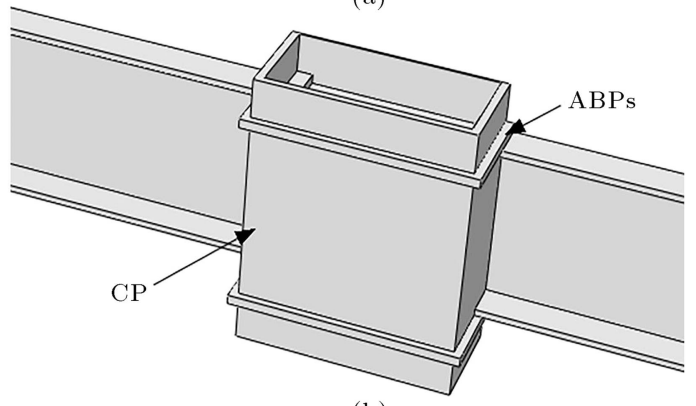

(b)

Figure 6. Joint details of models: (a) Model F-B-L-S and (b) model C-A. 
Table 2. Joint details of models.

\begin{tabular}{|c|c|c|c|c|c|c|c|c|c|}
\hline \multirow[b]{2}{*}{ Model } & \multicolumn{6}{|c|}{ Joint detail } & \multicolumn{3}{|c|}{ Steel beam flange thickness } \\
\hline & FBP & BP & Joint stirrup & SDP & $\mathbf{C P}$ & ABP & $\begin{array}{r}10.7 \mathrm{~mm} \\
(\text { IPE 300) } \\
\end{array}$ & $20 \mathrm{~mm}$ & $25 \mathrm{~mm}$ \\
\hline F-B-L-S & $\checkmark$ & $\checkmark$ & $\checkmark$ & $\checkmark$ & & & $\checkmark$ & & \\
\hline F-B-L & $\checkmark$ & $\checkmark$ & $\checkmark$ & & & & $\checkmark$ & & \\
\hline F-B-L-S (s) & $\checkmark$ & $\checkmark$ & $\checkmark$ & $\checkmark$ & & & & $\checkmark$ & \\
\hline F-L-S (s) & $\checkmark$ & & $\checkmark$ & $\checkmark$ & & & & $\checkmark$ & \\
\hline L-S (s) & & & $\checkmark$ & $\checkmark$ & & & & $\checkmark$ & \\
\hline $\mathrm{C}$ & & & & & $\checkmark$ & & $\checkmark$ & & \\
\hline $\mathrm{C}(\mathrm{s})$ & & & & & $\checkmark$ & & & $\checkmark$ & \\
\hline $\mathrm{S}-\mathrm{C}$ & & & & $\checkmark$ & $\checkmark$ & & $\checkmark$ & & \\
\hline $\mathrm{S}-\mathrm{C}(\mathrm{s})$ & & & & $\checkmark$ & $\checkmark$ & & & $\checkmark$ & \\
\hline $\mathrm{C}-\mathrm{A}$ & & & & & $\checkmark$ & $\checkmark$ & $\checkmark$ & & \\
\hline C-A (s) & & & & & $\checkmark$ & $\checkmark$ & & $\checkmark$ & \\
\hline L-S (ss) & & & $\checkmark$ & $\checkmark$ & & & & & $\checkmark$ \\
\hline F-L-S (ss) & $\checkmark$ & & $\checkmark$ & $\checkmark$ & & & & & $\checkmark$ \\
\hline F-B-L-S (ss) & $\checkmark$ & $\checkmark$ & $\checkmark$ & $\checkmark$ & & & & & $\checkmark$ \\
\hline $\mathrm{C}(\mathrm{ss})$ & & & & & $\checkmark$ & & & & $\checkmark$ \\
\hline $\begin{array}{l}\text { Note: F: Face be } \\
\text { C: Cover plate, }\end{array}$ & ing pl & & $\begin{array}{l}\text { Band plate, } \\
\text { Additional beari }\end{array}$ & plate, & $\begin{array}{l}\text { L: L- } \\
(\mathrm{s}):\end{array}$ & $\begin{array}{l}\text { hape joi } \\
\mathrm{mm} \text { fl }\end{array}$ & $\begin{array}{l}\text { irrup, } \\
\text { thickness, }\end{array}$ & $\begin{array}{l}\text { Steel doub } \\
\mathrm{s}): 25 \mathrm{~mm}\end{array}$ & $\begin{array}{l}\text { plate, } \\
\text { ge thickn }\end{array}$ \\
\hline
\end{tabular}

beam is increased to $20 \mathrm{~mm}$ to raise the beam flexural capacity. The flange thickness of steel beam in model L-S (ss) is increased to $25 \mathrm{~mm}$ and the longitudinal reinforcements are changed with $\Phi 22$ steel bars.

The performances of the models are compared in terms of lateral load-story drift response, joint shear forces, joint shear strain, bearing stress, and cracking pattern of concrete columns.

\subsection{Lateral load-story drift responses of simulated models}

3.2.1. Investigating the performance of $C P$ and $S D P$

The lateral load-story drift responses of the two simulated models are presented in Figure 7(a) to compare the performances of $\mathrm{CP}$ and SDP. As it is shown in this figure, the responses of models F-B-L-S and $\mathrm{C}$ are very similar. This indicates that using $\mathrm{CP}$ instead of the combination of SDP, FBP, band plate, and L-shape joint stirrups results in the same performance.

Figure $7(\mathrm{~b})$ shows that the load-story drift response of model $\mathrm{C}(\mathrm{s})$ is better than those of models F-L-S (s) and L-S (s), but lower than that of model F-B-L-S (s). The comparison between these models indicates that using CP instead of the combination of SDP and joint stirrups or the combination of SDP, FBP, and joint stirrups improves the performance of connection. However, using SDP and joint stirrups with both SBP and FBP in model F-B-L-S (s) makes its performance highly similar to the performance of model C (s). From constructability point of view, model C(s) is more practical in this group; this implies that it is the best model in the group of models with similar performances.

As it can be seen in Figure 7(c), the load-story drift response of model $\mathrm{C}$ (ss) is higher than those of models L-S (ss), F-L-S (ss), and F-B-L-S (ss). This proves that using CP instead of the combination of SDP and joint stirrups (comparison of models $\mathrm{C}(\mathrm{ss})$ and L-S (ss)), the combination of SDP and joint stirrups (comparison of models $\mathrm{C}$ (ss) and F-L-S (ss)), or even the combination of SDP, joint stirrups, SBP, and FBP (comparison of models $\mathrm{C}$ (ss) and F-B-L-S (ss)) improves the performance of the joint. As mentioned before, $\mathrm{CP}$ is more practical than each one of these combinations.

Overall, in all models with different types of details, the models with $\mathrm{CP}$ have higher performance in terms of lateral load-story drift response.

\subsubsection{Investigating the effect of $A B P s$ in models with $C P$}

Figure 8 shows that the performance of model $\mathrm{C}-\mathrm{A}$ is slightly higher than that of model $\mathrm{C}$, but in models with stronger steel beams (imposing higher forces on the joint region in models $\mathrm{C}(\mathrm{s})$ and $\mathrm{C}-\mathrm{A}(\mathrm{s}))$, the differences between the model with ABP and the model without this part are more remarkable. As can be seen, not only the ultimate capacity, but also the stiffness of model C-A ( $\mathrm{s}$ ) is higher than that of model C (s). 


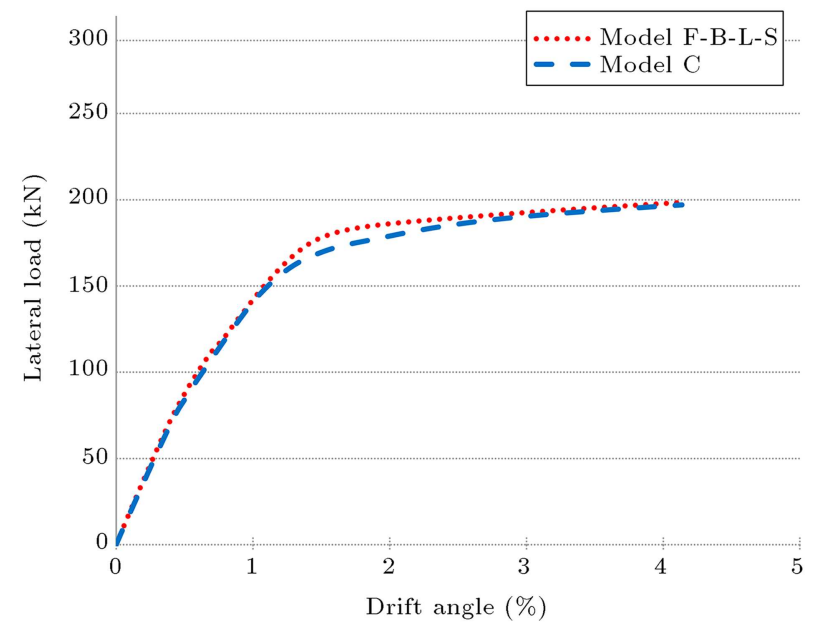

(a)

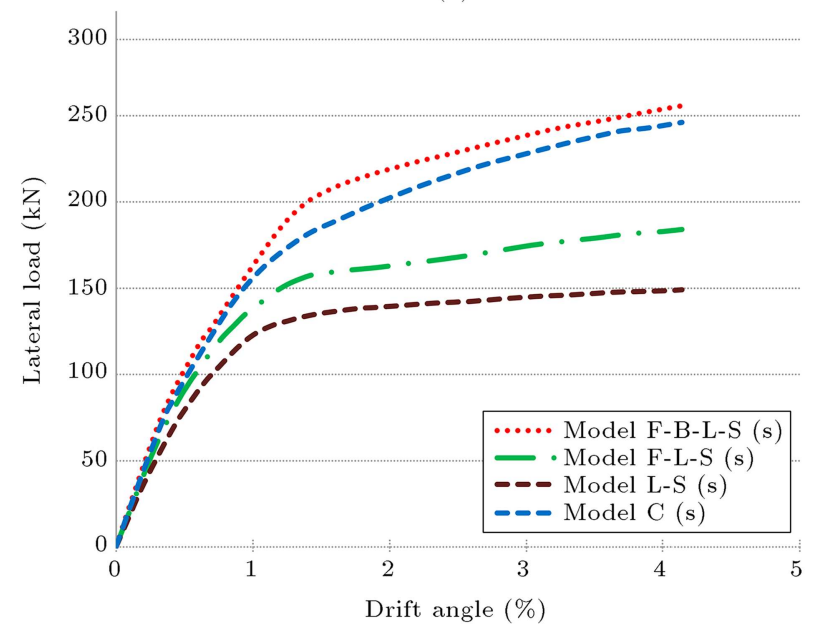

(b)

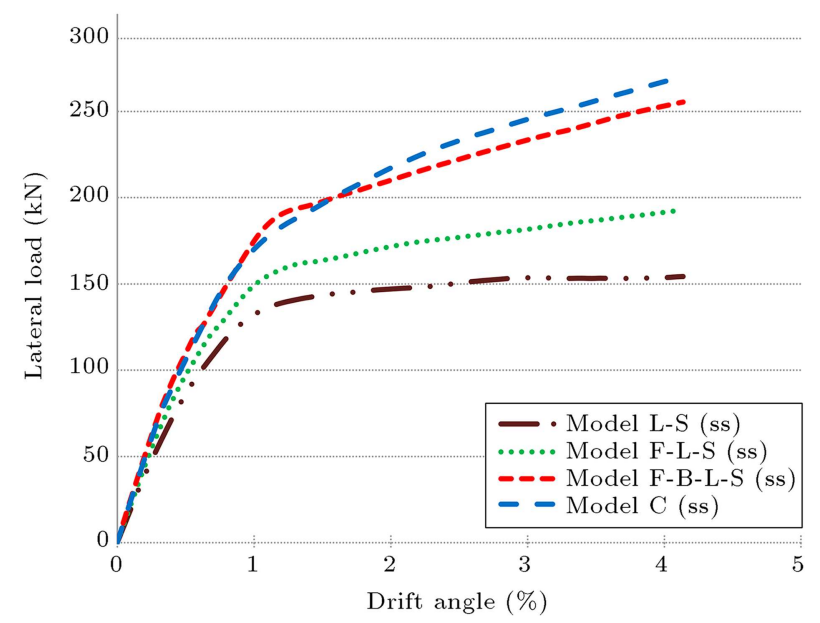

(c)

Figure 7. Lateral load-story drift responses of simulated models: (a) Model F-B-L-S, C, (b) models F-B-L-S (s), F-L-S (s), L-S (s), and C (s), and (c) models L-S (ss), F -L-S (ss), F-B-L-S (ss), and C (ss).

\subsection{Comparing internal joint shear forces}

In the simulated models, the joint shear strength is investigated by comparing the internal shear forces of

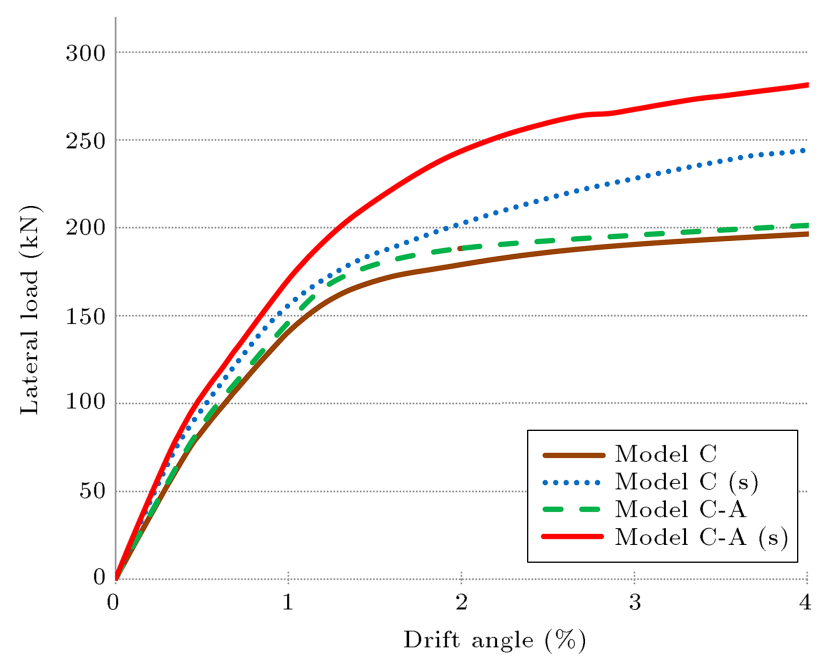

Figure 8. Lateral load-story drift responses of models C, $\mathrm{C}(\mathrm{s}), \mathrm{C}-\mathrm{A}$, and C-A (s).

joint shear mechanisms. The internal shear forces are captured from the middle of the inner concrete panel, outer concrete panel, steel beam web panel, and (CP). Inner concrete panel is the concrete region between two flanges of steel beam and outer concrete panel is located outside the steel flange width. Table 3 shows the contribution percentages of the internal shear forces of joint shear mechanisms in all the simulated models.

3.3.1. Investigating the performances of $C P$ and $S D P$ The results in Table 3 indicate that using CP instead of the combination of steel doubler plate and joint stirrups increases the participation of inner concrete panel and reduces steel beam web participation. Therefore, the distribution of internal joint shear forces becomes more effective.

\subsubsection{Investigating the effect of $A B P s$ in models with $C P$}

Comparing models $\mathrm{C}$ and $\mathrm{C}-\mathrm{A}$ based on Table 3 indicates that using $\mathrm{ABP}$ reduces the concrete panel participation while the steel beam web participation increases. On the other hand, comparison between models $\mathrm{C}(\mathrm{s})$ and $\mathrm{C}-\mathrm{A}(\mathrm{s})$ shows that using ABP transfers the forces from steel beam web to $\mathrm{CP}$ and makes CP more effective; in addition, it leads to reduction in the concrete panel participation. The difference between these two groups is in beam capacity and it can be inferred that in beams with higher capacity, ABPs can help to transfer the forces from the steel web to $\mathrm{CP}$.

\subsection{Cracking and failure modes}

The main failure mechanisms of the models are tensile concrete cracking and steel beam yielding. The tensile damages to columns and Von-Misses stresses of steel beams at $4 \%$ story drift are shown in Figures 9 and 10, respectively. 
Table 3. Contribution percentages of internal shear forces of joint shear mechanisms.

\begin{tabular}{|c|c|c|c|c|c|c|c|c|}
\hline \multirow[b]{2}{*}{ Story drift } & \multicolumn{2}{|c|}{$\begin{array}{c}\text { Inner concrete } \\
\text { panel }\end{array}$} & \multicolumn{2}{|c|}{$\begin{array}{c}\text { Outer concrete } \\
\text { panel }\end{array}$} & \multicolumn{2}{|c|}{$\begin{array}{c}\text { Steel beam } \\
\text { web }\end{array}$} & \multicolumn{2}{|c|}{$\begin{array}{l}\text { Cover } \\
\text { plate }\end{array}$} \\
\hline & $1 \%$ & $3 \%$ & $1 \%$ & $3 \%$ & $1 \%$ & $3 \%$ & $1 \%$ & $3 \%$ \\
\hline Model F-B-L-S & 16.02 & 18.9 & 20.73 & 12.27 & 63.25 & 68.82 & - & - \\
\hline Model F-B-L & 23.11 & 30.31 & 24.99 & 24.41 & 51.9 & 45.28 & - & - \\
\hline Model F-B-L-S (s) & 15.01 & 20.76 & 18.09 & 15.43 & 66.90 & 63.82 & - & - \\
\hline Model F-L-S (s) & 11.73 & 13.1 & 17.84 & 13.53 & 70.42 & 73.42 & - & - \\
\hline Model L-S (s) & 2.6 & 0.75 & 11.12 & 11.74 & 86.27 & 87.49 & - & - \\
\hline Model C & 22.42 & 22.35 & 21.88 & 13.03 & 43.57 & 34 & 12.14 & 30.62 \\
\hline Model C (s) & 21.07 & 20.84 & 18.10 & 12.11 & 42.95 & 31.97 & 17.88 & 35.09 \\
\hline Model S-C & 15.79 & 14.23 & 14.69 & 10.26 & 59.27 & 63.71 & 10.25 & 11.8 \\
\hline Model S-C (s) & 14.91 & 15.56 & 13.28 & 7.92 & 59.53 & 52.67 & 12.28 & 23.85 \\
\hline Model C-A & 16.24 & 11.77 & 14.92 & 12.39 & 49.67 & 55.47 & 19.17 & 20.38 \\
\hline Model C-A (s) & 16.46 & 16.51 & 17.73 & 14.32 & 38.45 & 26.33 & 27.37 & 42.85 \\
\hline Model L-S (ss) & 2.17 & 0.49 & 12.74 & 12.45 & 85.08 & 87.04 & - & - \\
\hline Model F-L-S (ss) & 11.16 & 15.41 & 15.57 & 12.77 & 73.25 & 71.80 & - & - \\
\hline Model F-B-L-S (ss) & 10.16 & 12.96 & 16.61 & 16.93 & 73.21 & 70.09 & - & - \\
\hline Model C (ss) & 21.46 & 21.69 & 18.27 & 12.27 & 39.64 & 30.49 & 20.16 & 35.53 \\
\hline
\end{tabular}

The cracking pattern on the face of the joint region indicates the formation of diagonal compression struts in the concrete panel. Figure 9(a) shows the crack patterns of models F-B-L-S, C, S-C, and C-A. As can be seen, the joint region of model F-B-L-S experiences the greatest damage in terms of tensional cracks due to the insufficiency of concrete confinement. On the other hand, in model $\mathrm{C}$, cracks at the joint region are reduced, because $\mathrm{CP}$ increases the concrete confinement. This reduction is more remarkable in model S-C with CP and SDP. However, differences between crack patterns in models $\mathrm{C}$ and $\mathrm{S}-\mathrm{C}$ are very slight and can be neglected.

In addition, diagonal cracks of model F-B-L-S start at $0.6 \%$ story drift and in model $\mathrm{C}$, diagonal and flexural cracks can be observed at about $0.65 \%$ drift story. On the other hand, flexural crack begins to appear at about $0.58 \%$ drift story and diagonal cracks start at $0.65 \%$ story drift in model S-C. As can be seen, using CP instead of SDP causes the formation of cracks to occur at higher story drifts.

In the comparison between models $\mathrm{C}$ and $\mathrm{C}-\mathrm{A}$, it can be seen that Model C-A shows fewer cracks because of using $\mathrm{CP}$ and $\mathrm{ABP}$, which can increase the concrete confinement and transfer the imposed forces to the CP. Comparison of the performances of models S-C and $\mathrm{C}-\mathrm{A}$ indicates that using $\mathrm{ABP}$ in combination with $\mathrm{CP}$ can noticeably improve the concrete confinement and decrease the joint region damages. Overall, it can be concluded that $\mathrm{CP}$ in combination with $\mathrm{ABP}$ can work better than CP in combination with SDP, and can improve the joint region performance and increase its strength and stiffness.

Figure 9(b) shows the cracking patterns of the second group of models with stronger beams than the first group. Therefore, the cracks in this group are more than those in the first group. In this group, model C (s) has the lowest number of cracks because of using CP instead of SDP with or without FBP and SDP, which leads to better confinement of concrete in the joint region. Furthermore, the lack of FBPs in 5 s results in weak transfer of force from steel beam to concrete and leads to fewer cracks in model L-S (s) than in model F-L-S (s).

Diagonal and flexural cracks of the column of model C (s) occur at $0.62 \%$ story drift and in model F-L-S (s), flexural cracks start at $0.6 \%$ story drift and diagonal cracks can be observed at about $0.9 \%$ story drift. On the other hand, flexural cracks start to occur at about $0.73 \%$ story drift and diagonal cracks start at approximately $1 \%$ story drift in model L-S (s). It can be seen that the lack of SBP or FBP causes the cracks to occur at higher story drifts, because in these models, concrete cannot participate as properly as it does in models with $\mathrm{CP}$ (model $\mathrm{C}(\mathrm{s})$ ), and the beam should tolerate a higher shear force.

The cracks of the columns of the third group at $4 \%$ story drift are presented in Figure 9(c). As it can be seen, this figure shows the same result as Figure 9(b) does, but cracks in this group are fewer than those 


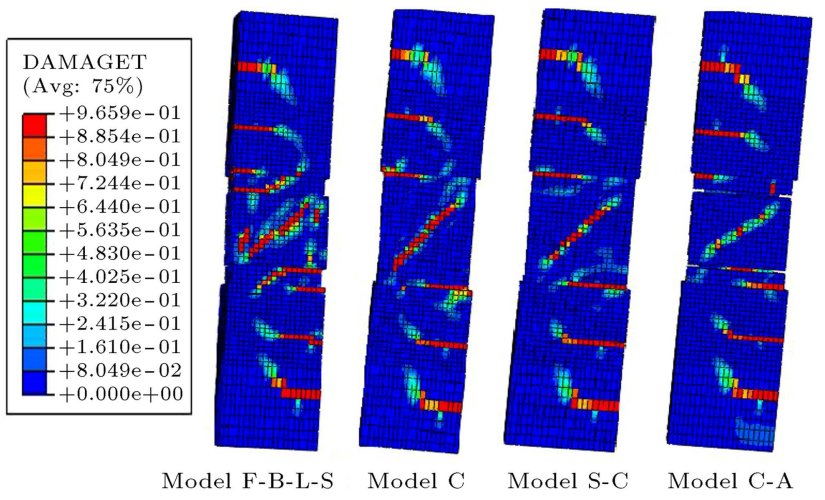

(a)
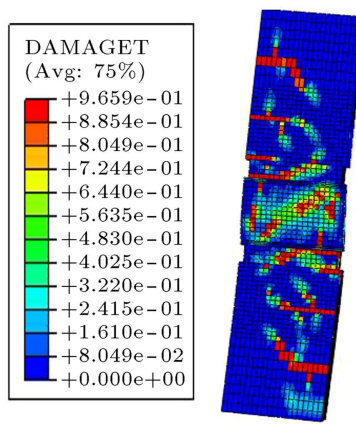

Model F-B-L-S(s) Model F-L-S(s)

(b)
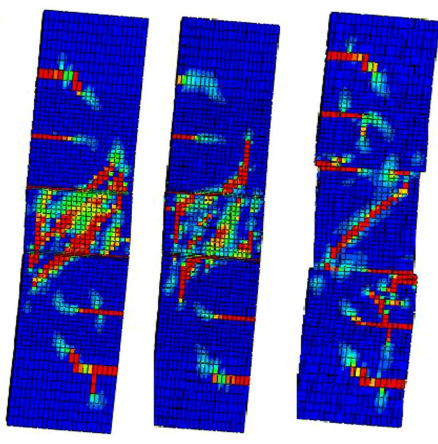

Model C (s)
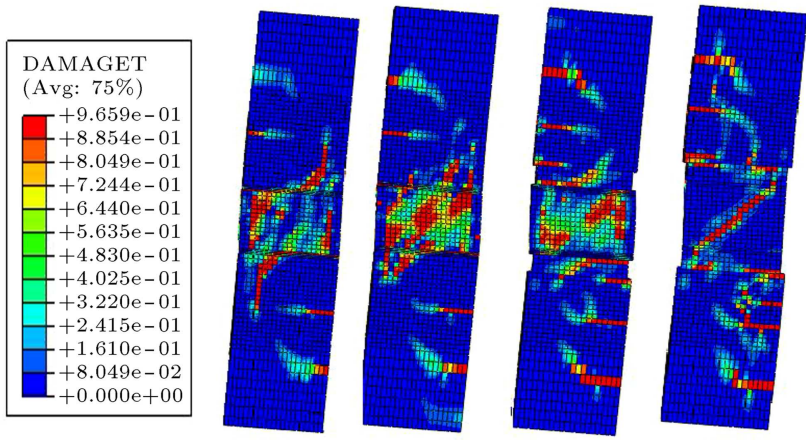

Model L-S(ss) Model F

(c)

Figure 9. Tension cracks in models at $4 \%$ story drift: (a) Models F-B-L-S, C, S-C, and C-A; (b) Models F-B-L-S (s), F-L-S (s), L-S (s), and C (s), and (c) Models L-S (ss), F -L-S (ss), F-B-L-S (ss), and C (ss).

in the second group because of using stronger beams and reinforcement bars. Like in the second group, the model with CP (model C (ss)) has the fewest cracks. As can be seen, in the first group of models, the governing failure mode is beam yielding. In the second group of models, the capacity of steel beam increases by raising the flange thickness to $20 \mathrm{~mm}$. In these models, failure occurs in the panel zone because of increase in the imposed forces on the joint. In other models, flange thickness increases to $25 \mathrm{~mm}$ and the diameter of longitudinal steel bars of the columns increases to
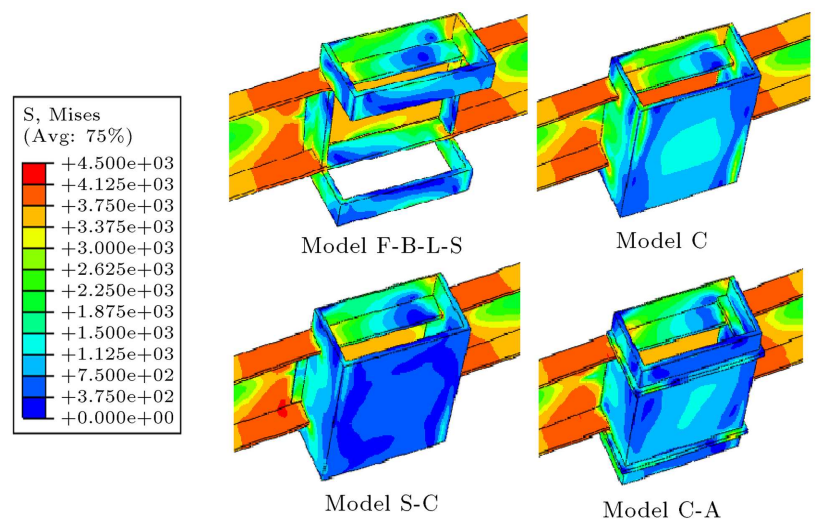

(a)
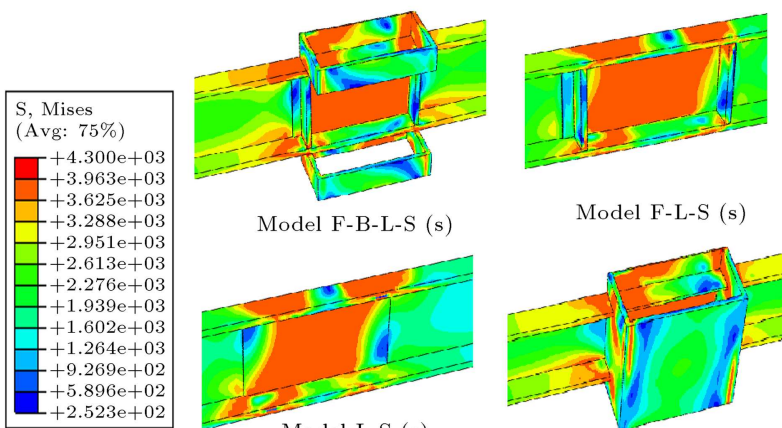

Model F-B-L-S (s)

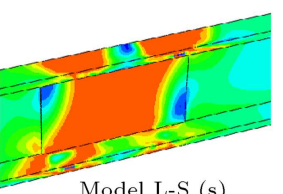

Model F-L-S (s)

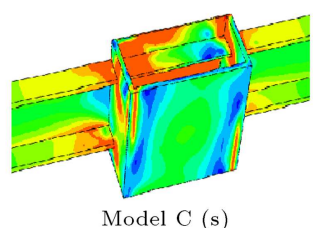

(b)
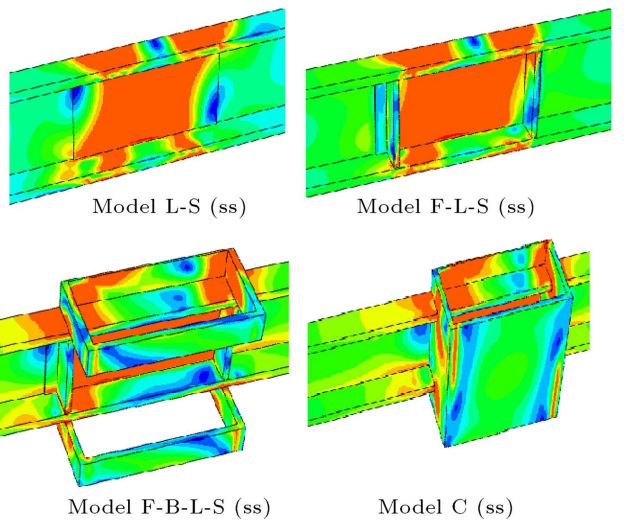

Model C (ss)

(c)

Figure 10. Stress of beams in models at $4 \%$ story drift: (a) Models F-B-L-S, C, S-C, and C-A, (b) models F-B-L-S (s), F-L-S (s), L-S (s), and C (s), and (c) models L-S (ss), F -L-S (ss), F-B-L-S (ss), and C (ss).

$\Phi 22$. The third group of models is designed such that failure modes are concentrated in the panel zone.

Figure 10 shows the Von-Misses stress contours of the beams of the models. The figure shows that the steel beam web in the joint region of the models without $\mathrm{CP}$ experiences a higher level of stresses. On the other hand, the efficiency of CPs models $\mathrm{C}$ and $\mathrm{S}-\mathrm{C}$ is lower than that in model C-A due to the lack of stiffeners for transferring the joint forces to the CP. Also, when $\mathrm{CP}$ is used in combination with SDP in a model (model 
S-C), CP does not work effectively. Some joint details like ABP increase joint stiffness, decrease joint shear lag, and improve participation of $\mathrm{CP}$ in the joint shear strength and stiffness.

In addition, in model F-B-L-S, beam yielding starts at about $1 \%$ drift and plastic hinge forms in the flange of the beam at $1.9 \%$ story drift. Beam yielding in model $\mathrm{C}$ and model S-C starts at approximately $0.95 \%$ and $0.85 \%$ story drift, respectively.

Based on Figure 10(a), CP performs better in models with ABP (comparing model C-A with model C), because ABPs help to transfer force from steel beam to $\mathrm{CP}$ more efficiently.

As can be seen in Figure 10(b), the performance of model $\mathrm{C}(\mathrm{s})$ (with $\mathrm{CP}$ ) is better than models $\mathrm{L}-$ $\mathrm{S}(\mathrm{s})$ (with SDP), F-L-S (s) (with SDP and FBP), and F-B-L-S (s) (with SDP, FBP, and SBP), because $\mathrm{CP}$ transfers forces to the concrete properly. Such distribution brings stresses in the flanges of model $\mathrm{C}$ (s) lower than those in other models of this group.

In addition, beam yielding in model F-B-L-S ( $\mathrm{s}$ ) starts from its flange at $0.55 \%$ story drift and steel web of beam starts to yield at $1.14 \%$ story drift. In model F-L-S (s), yielding of steel web starts at $1.08 \%$ story drift and yielding of flange starts slightly later, at $1.17 \%$ story drift. In model L-S (s), flange starts to yield at $0.63 \%$ story drift and in web, it starts at $0.83 \%$ story drift. However, in model $\mathrm{C}(\mathrm{s})$, yielding starts simultaneously in web and flange of the beam at $0.84 \%$ story drift. It can be concluded that models with CP start to yield at higher story drift levels than models with SDP do.

In Figure 10(c), it can be seen that the third group of models shows similar results to those of the second group. Also, the distribution of stresses in models of this group is very similar to that in the second group.

The steel beam in model L-S (ss) starts to yield in both flange and web of the steel beam simultaneously at $0.76 \%$, while yielding in model $\mathrm{C}$ (ss) originates in the web at $0.73 \%$ story drift and at $0.93 \%$ story drift, flange yielding starts. Since there is a direct correlation between these values and stiffness of the joints, it can be concluded that the joint region of the model with CP instead of SDP (model C (ss)) performs better in terms of strength and stiffness than that of the model with SDP (model L-S (ss)) does.

\subsection{Shear strain}

For better understanding of the shear behavior of different joint details, the shear strains of the joint shear mechanisms are depicted in Figures 11, 12, and 13. The strains are recorded from the middle of the steel beam web, CP, and the inner and outer concrete panels.

The shear strains of the inner concrete panel are shown in Figure 11(a). It can be seen that shear

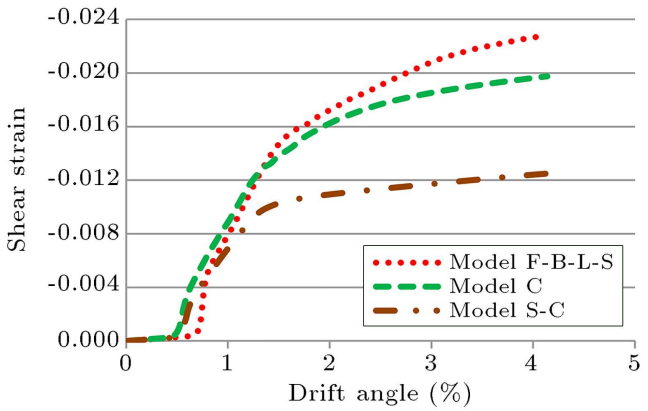

(a)

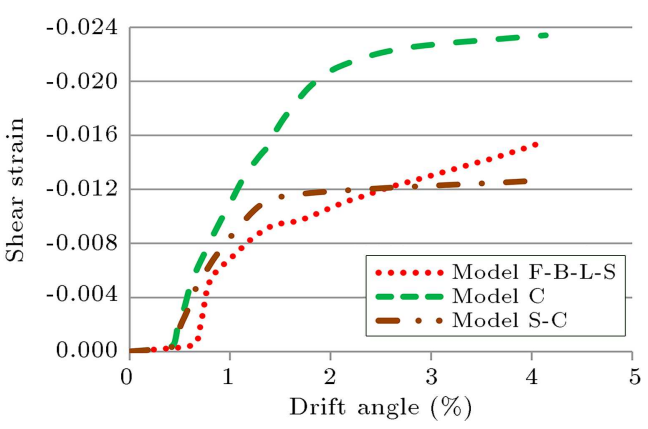

(b)

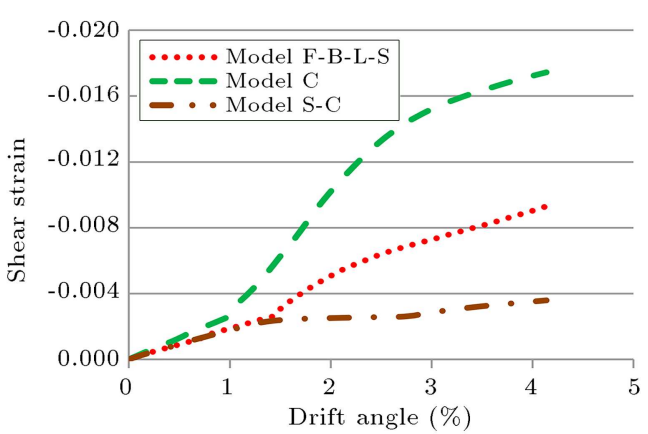

(c)

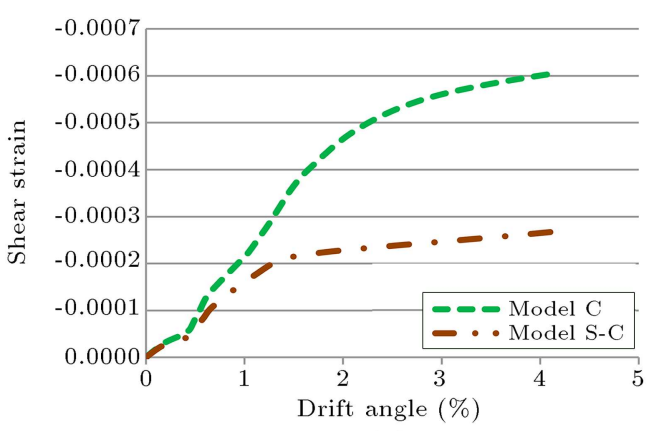

(d)

Figure 11. Shear strains in the joint shear mechanisms of models F-B-L-S, C, and S-C: (a) Inner concrete panel, (b) outer concrete panel, (c) steel beam web, and (d) Cover Plate (CP).

strain immediately increases in all of the models at about $0.75 \%$ story drift. The shear strain of the inner concrete panel in model $\mathrm{S}-\mathrm{C}$ is half that in model F-B-L-S due to using CP. The shear strain of the inner concrete panel in model $\mathrm{C}$ is about $20 \%$ lower than that in model F-B-L-S because of using CP 


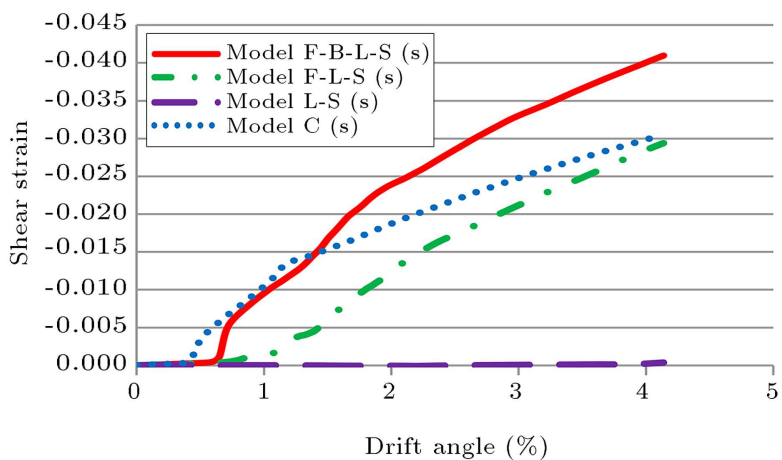

(a)

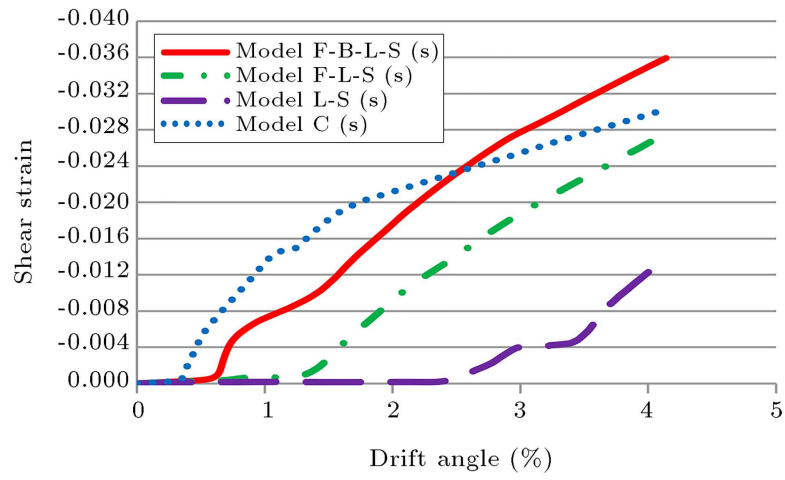

(b)

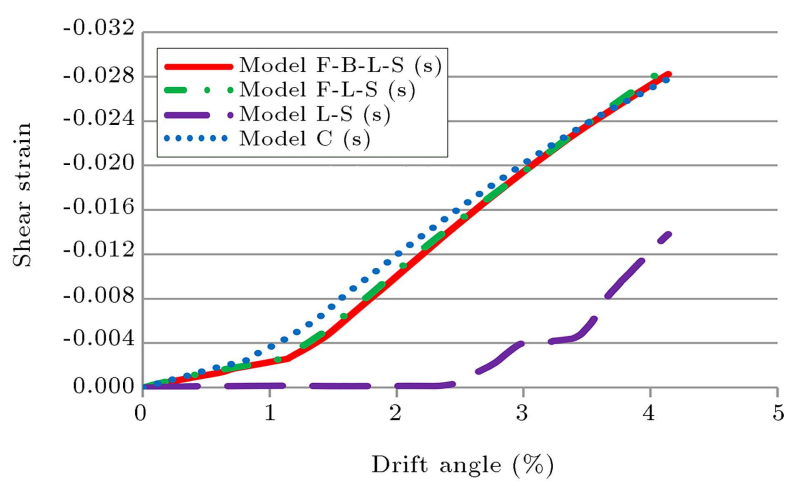

(c)

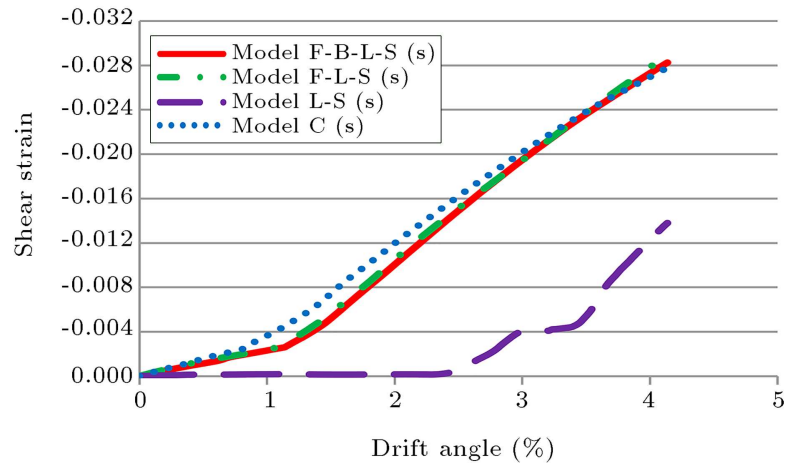

(d)

Figure 12. Shear strains in the joint shear mechanisms in models F-B-L-S (s), F-L-S (s), L-S (s), and C (s): (a) Inner concrete panel, (b) outer concrete panel, (c) steel beam web, and (d) Cover Plate (CP).

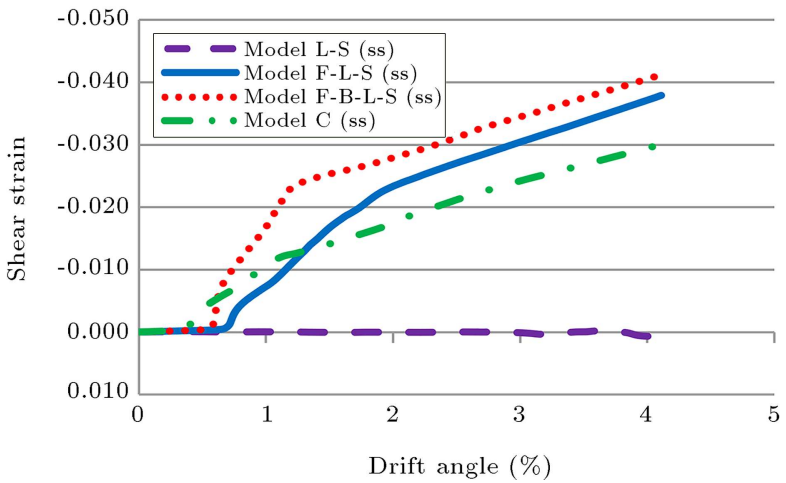

(a)

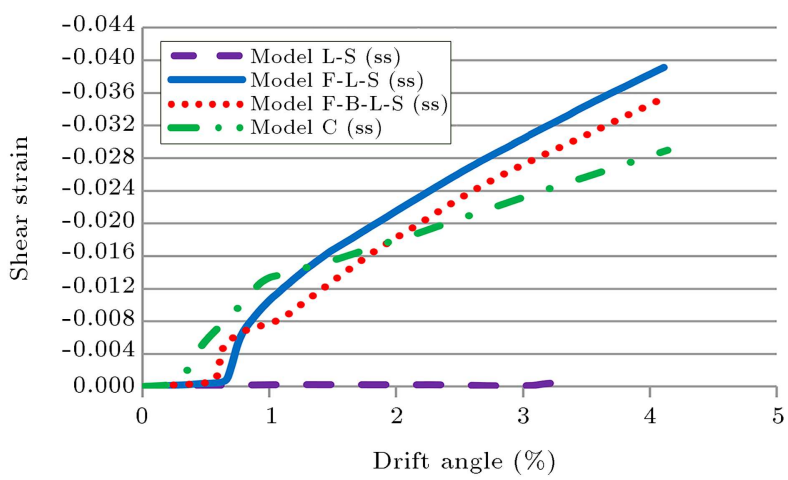

(b)

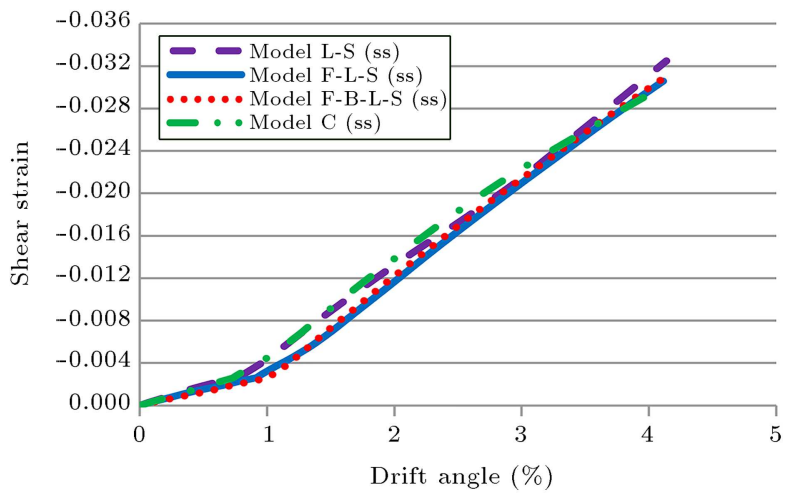

(c)

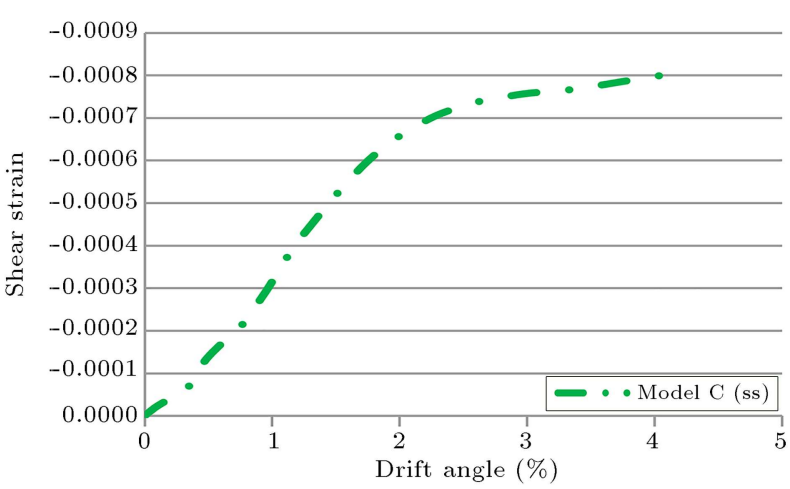

(d)

Figure 13. Shear strains in the joint shear mechanisms in models L-S (ss), F -L-S (ss), F-B-L-S (ss), and C (ss): (a) Inner concrete panel, (b) outer concrete panel, (c) steel beam web, and (d) Cover Plate (CP). 
instead of SDP. However, by comparing models F-B$\mathrm{L}-\mathrm{S}$ and $\mathrm{C}$ based on the information in Figure 11(b), it can be deduced that using $\mathrm{CP}$ instead of SDP causes about $50 \%$ increase in shear strain of the outer concrete panel, because $\mathrm{CP}$ creates a good confinement that causes more participation of the outer concrete panel.

In Figure 11(c), it is shown that the shear strain in the steel beam web of model $\mathrm{C}$ has the highest value, which is about 0.017 , because of the lack of SDP. Comparing the models F-B-L-S and S-C shows that using CP leads to about 2.6 times decrease in shear strain of the steel beam web. Figure 11(d) illustrates the effects of removing the SDP in models with $\mathrm{CP}$. Comparison of models $\mathrm{C}$ and $\mathrm{S}-\mathrm{C}$ based on the figure shows that eliminating doubler plate can help to use CP more effectively.

The shear strains of the inner concrete panels in models with stronger beams are shown in Figure 12(a). As can be seen, the shear strain of the inner concrete panel in model $\mathrm{C}(\mathrm{s})$ indicates an increase at $0.5 \%$ story drift and it reaches the peak value of about -0.03 at $4 \%$ story drift. This increase in model F-B-L-S (s) occurs at $0.75 \%$ story drift and the shear strain reaches the peak value of about -0.041 at $4 \%$ story drift. However, in the other two models, we can see that shear strains of the inner concrete are much lower than that of model $\mathrm{C}(\mathrm{s})$. The results show that using CP instead of SDP (comparing models $\mathrm{C}(\mathrm{s})$ and L-S (s)) can increase the contribution of the outer concrete panel to joint shear strength and stiffness. The same results can be obtained from Figure 12(b).

The recorded shear strains of the steel beam web are provided in Figure 12(c). According to this figure, the shear strains of models F-B-L-S (s), F-L-S (s), and $\mathrm{C}(\mathrm{s})$ are nearly the same; however, model L-S (s) with SDP does not have the same result. Therefore, using CP instead of SDP can lead to the same result or even increase the contribution of steel beam to joint shear strength and stiffness.

As seen in Figure 13(a) and (b), increasing the capacity of beams and column can increase the shear strain of concrete panel in models with SDP, with or without SBP; however, in model L-S (ss) with SDP and joint stirrups, the concrete panel does not experience any shear strain.

Figure 13(c) shows the same shear performance of steel beam in all models. This may result from increase in capacity of the beam. Also, it shows that using neither CP nor SDP affects the shear performance of these models.

In Figures 11(d), 12(d), and 13(d), it can be seen that enhancing the capacity of beams without increasing the $\mathrm{CP}$ thickness raises the shear strain of CPs.

Due to the specific load path in RCS connections,

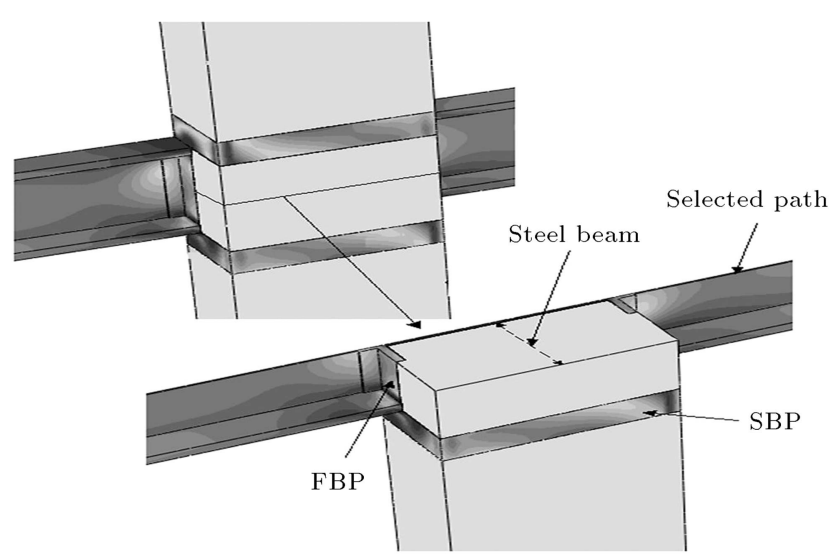

Figure 14. Selected path for recording joint shear strains.

shear lag occurs between steel beam web and the outer concrete panel. The shear lag effect varies with different joint details. In this research, shear lag is investigated by defining a path in the middle of the joint, which is shown in Figure 14. Shear strains are recorded in this path at $3 \%$ story drift and provided in Figure 15.

As can be seen in Figure 15(a), the shear lag in model $\mathrm{C}$ is the lowest, because $\mathrm{CP}$ creates confinement in the joint region, while model F-B-L-S shows the highest shear lag by using SDP without CP, which makes the beam stronger without improving the confinement of concrete. Overall, using SDP can decrease the shear strains of steel beam web, and using CP improves the concrete confinement and decreases joint shear lag.

According to Figure 15(b), model C (s) shows the lowest shear lag, and concrete panels and CP contribute effectively to joint shear strength due to using $\mathrm{CP}$ instead of SDP. On the other hand, model L-S (s) (the model with SDP without CP) shows the lowest shear strain, because the connection is strengthened using SDP; however, there is not any confinement placed on the concrete panel in this model (Figure 15(c)).

\subsection{Bearing stress}

The failure mechanisms of beam-through-type RCS connections are joint shear failure and joint bearing failure. In the previous sections, the shear behavior of this type of connections was investigated and in this section, its bearing performance is studied.

Bearing failure of RCS connections is due to high compression stresses in the concrete adjacent to steel beam. In this section, the bearing behavior of RCS connections is studied by recording the bearing stresses of concrete. Figure 16 shows the selected element for capturing the stress.

The recorded bearing stresses are depicted in Figure 17. Comparing models F-B-L-S and C based on Figure 17(a) shows that using CP instead of SDP increases the stiffness and reduces the bearing stress. 


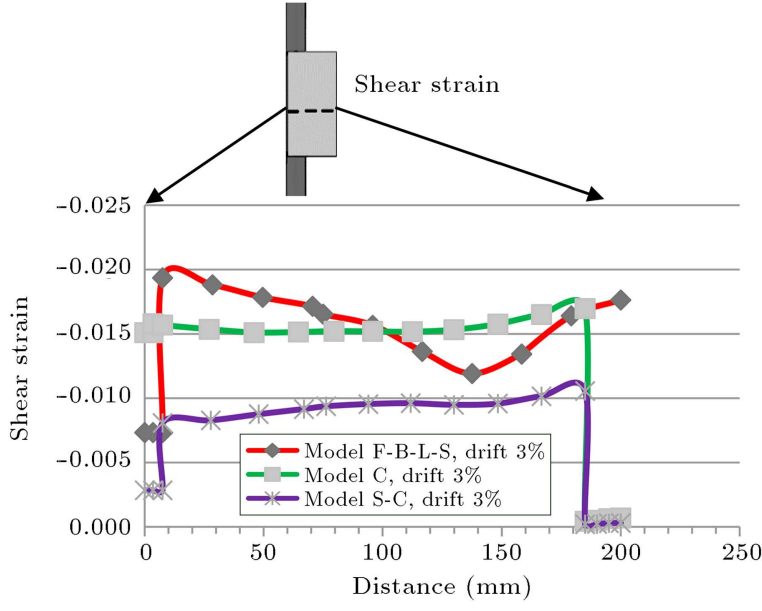

(a)

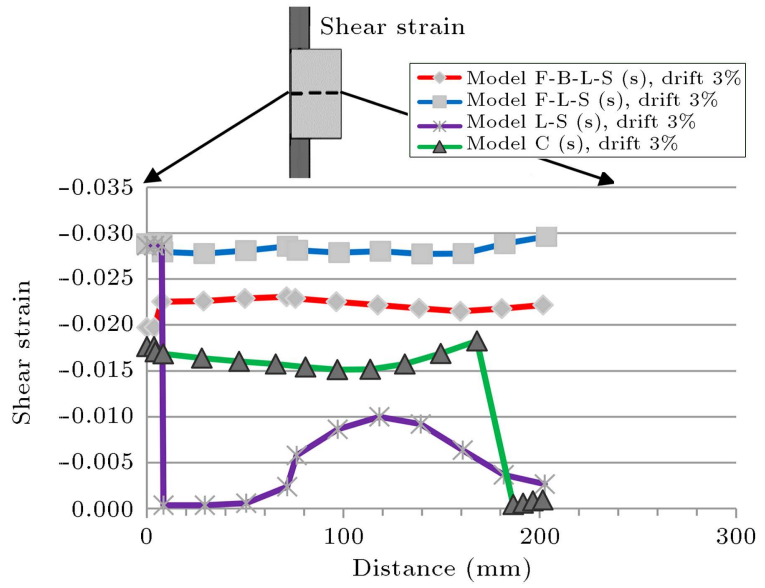

(b)

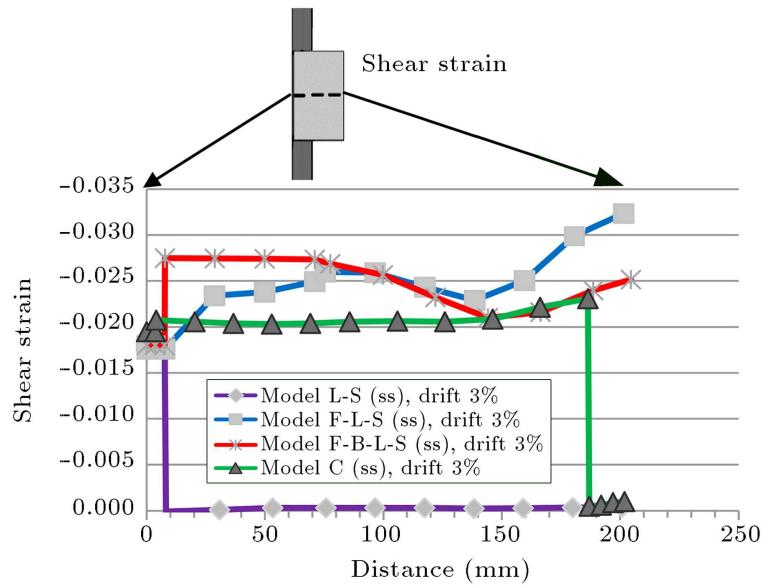

(c)

Figure 15. Shear strain at the middle of the connection: (a) Models F-B-L-S, C, and S-C, (b) models F-B-L-S (s), F-L-S (s), L-S (s), and C (s), and (c) models L-S (ss), F-L-S (ss), F-B-L-S (ss), and C (ss).

Also, comparison between models $\mathrm{C}$ and $\mathrm{S}-\mathrm{C}$ shows that using SDP in the model with $\mathrm{CP}$ can reduce the bearing stresses, but cannot improve the model significantly. In Figure 17(b), it can be seen that

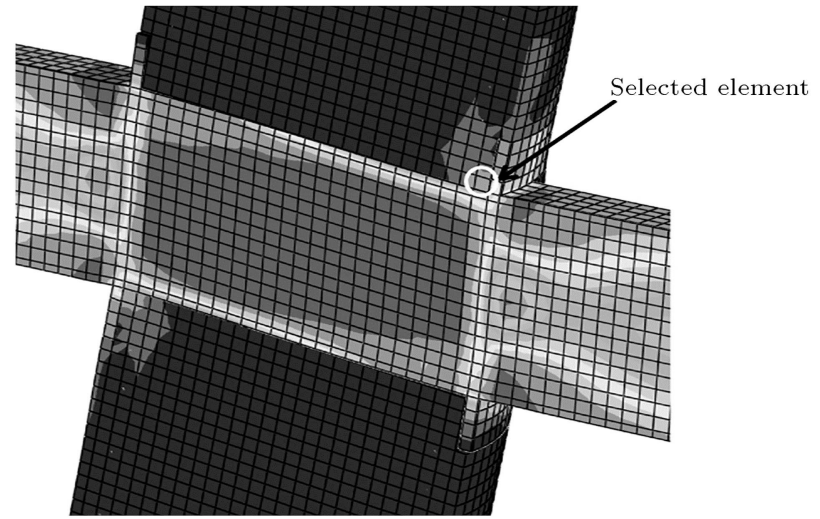

Figure 16. Selected element for recording bearing stresses.

in models with stronger beams, the same result is obtained.

According to Figure 17(c), model C (ss) shows the lowest bearing stresses by making concrete confinement until drift $2.2 \%$, while at higher drifts, the model has similar results with models L-S (ss), F-L-S (ss), and F-B-L-S (ss) that have SDP. At drift levels higher than 3.5, models with SDP show better performance.

\section{Conclusion}

In this paper, 15 interior beam-through-type RCS connections were simulated using a nonlinear threedimensional finite element method using ABAQUS [21] software and verified with the experimental tests of Alizadeh et al. [11]. The aim of this study was to investigate the performance of CPs and ABPs. The performances of the models were compared in terms of load-story drift response, joint shear forces, joint bearing stress, shear strains at joint region, steel beam stresses, and concrete cracking pattern. Based on the results of this study, the following conclusions were made:

It was observed that using $\mathrm{CP}$ and removing joint stirrups were more practical than using SDP and joint stirrups with or without SBP and FBP. Based on the lateral load-story drift responses of the simulated models, it was concluded that using CP instead of the combination of Steel Band Plates (SBPs), FBP, and joint stirrups was useful to keep the same performance of the model. On the other hand, in this study, using $\mathrm{CP}$ led to reduction in steel beam web participation in joint shear force and increase in CP and inner concrete panel participations. At $4 \%$ story drift, fewer cracks were observed, because $\mathrm{CP}$ well confined the concrete. Using CP instead of steel doubler plate led to increase in shear strains in the outer concrete panel and steel beam web and decrease in shear strain in the inner concrete panel, bearing stress, and shear lag in the joint region. 


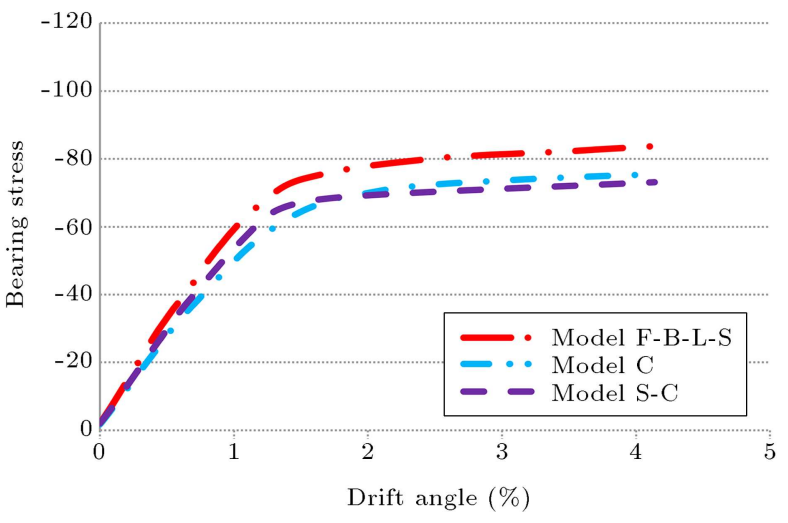

(a)

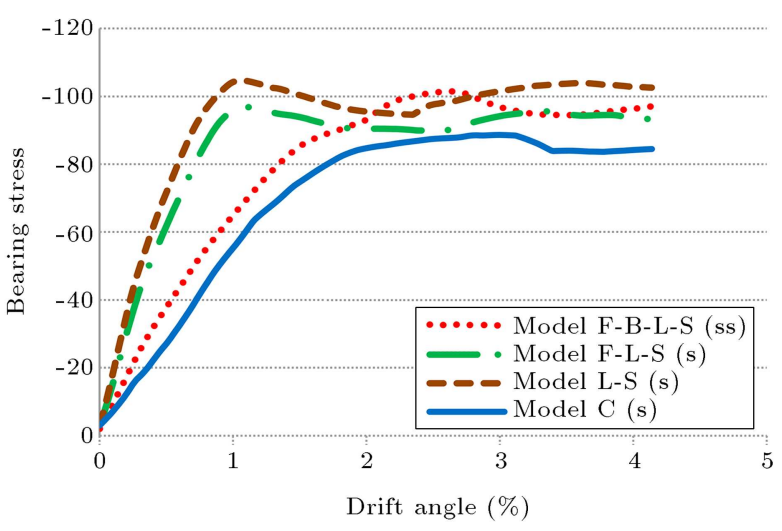

(b)

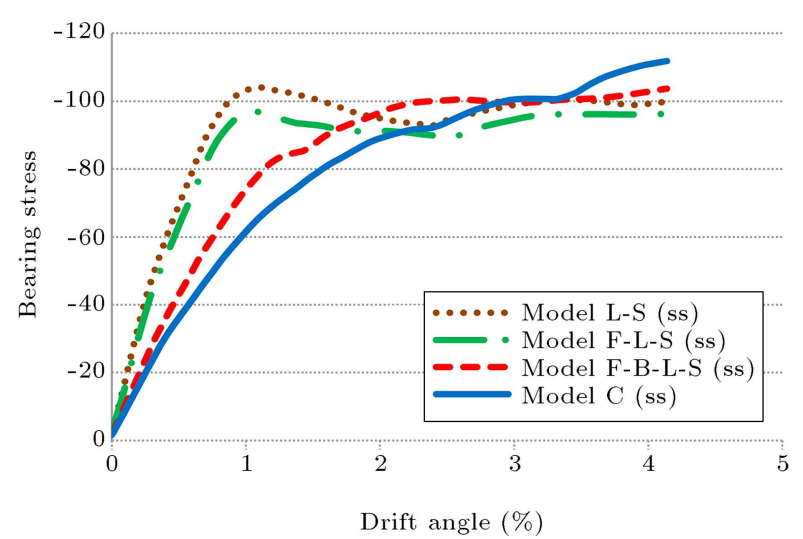

(c)

Figure 17. Bearing stresses in concrete: (a) Models F-B-L-S, C, and S-C, (b) models F-B-L-S (s), F-L-S (s), L-S (s), and C (s), and (c) models L-S (ss), F -L-S (ss), F-B-L-S (ss), and C (ss).

Results showed that using ABP with $\mathrm{CP}$ could improve the performance, and diminish the participation of SDP and enhance the participation of CP. In addition, it helped the $\mathrm{CP}$ to better confine the concrete so that fewer cracks formed in the joint region. The SDP in these models tolerated lower stress, because ABPs helped to transfer force from steel beam to $\mathrm{CP}$ more efficiently.

\section{References}

1. Sakaguchi, N., Tominaga, H., Murai, Y., Takase, Y., and Shuto, K. "Strength and ductility of steel beamRC column connection", In Proc. 9th World Conf. on Earthquake Engineering, IV. Tokyo-Kyoto (Japan), pp. 713-718 (1988).

2. Bugeja, M.N. "Seismic behavior of composite moment resisting frame systems", PhD Dissertation, Texas A\&M University, USA (1999).

3. Machelski, Cz. and Toczkiewicz, R. "Effects of connection flexibility in steel-concrete composite beams due to live loads", Archives of Civil and Mechanical Engineering, 6(1), pp. 65-86 (2006).

4. Eghbali, N.B. and Mirghaderi, S.R. "Experimental investigation of steel beam to $\mathrm{RC}$ column connection via a through-plate", Journal of Constructional Steel Research, 133, pp. 125-140 (2017).

5. Nguyen, X.H., Nguyen, Q-H., Le, D.D., and Mirza, O. "Experimental study on seismic performance of new RCS connection", In Structures, 9, pp. 53-62 (2017).

6. Mirghaderi, S.R., Eghbali, N.B., and Ahmadi, M.M. "Moment-connection between continuous steel beams and reinforced concrete column under cyclic loading", Journal of Constructional Steel Research, 118, pp. 105-119 (2016).

7. Qi, H.T., Guo, L.H., Liu, J.P., et al. "Axial load behavior and strength of tubed steel reinforced-concrete (SRC) stub columns", Thin-Walled Structures, 49(9), pp. 1141-1150 (2011).

8. Ho, J.C.M. and Dong, C.X. "Improving strength, stiffness and ductility of CFDST columns by external confinement", Thin-Walled Structures, 75, pp. 18-29 (2014).

9. Wróblewski, T., Berczyński, S., and Abramowicz, M. "Estimation of the parameters of the discrete model of a steel-concrete composite beam", Archives of Civil and Mechanical Engineering, 13, pp. 209-219 (2013).

10. Cai, J., Pan, J., and Wu, Y. "Mechanical behavior of steel-reinforced concrete-filled steel tubular (SRCFST) columns under uniaxial compressive loading", ThinWalled Structures, 97, pp. 1-10 (2015).

11. Alizadeh, S., Attari, N.K.A., and Kazemi, M.T. "Experimental investigation of RCS connections performance using self-consolidated concrete", Journal of Constructional Steel Research, 114, pp. 204-216 (2015).

12. Alizadeh, S., Attari, N.K.A., and Kazemi, M.T. "The seismic performance of new detailing for RCS connections", Journal of Constructional Steel Research, 91, pp. 76-88 (2013).

13. Nguyen, Q.H., Hjiaj, M., Nguyen, X.H., and Nguyen, H.C. "Finite element analysis of a hybrid RCS beamcolumn connection", The 3rd International Conference CIGOS 2015: Innovations in Construction, Paris, France (2015). 
14. Men, J., Zhang Y., Guo, Z., and Shi, Q. "Experimental research on seismic behavior of a composite RCS frame", Steel and Composite Structures, 18(4), pp. 971-983 (2015).

15. Chou, C-C. and Chen, J. "Tests and analyses of a fullscale post-tensioned RCS frame subassembly", Journal of Constructional Steel Research, 66(11), pp. 13541365 (2010).

16. Shen, H.X. "Nonlinear finite element analysis of exterior RC column-to-steel beam connection", International Conference on Computer Application and System Modeling (ICCASM), XiaMen, China (Oct. 2010).

17. Zhang, Q., Yu, Q., Guan, J., and Wu, Z. "Seismic behavior of confined RC column-composite beam joints", Transactions of Tianjin University, 20(3), pp. 174-181 (2014).

18. Li, W., Li, Q.N., Jiang, L., and Jiang W.S. "Seismic performance of composite reinforced concrete and steel moment frame structures-state-of-the-art", Composites Part B, 42(2), pp. 190-206 (2011).

19. Farahmand Azar, B., Ghaffarzadeh, H., and Talebian, N. "Seismic performance of composite RCS special moment frames", KSCE Journal of Civil Engineering, $\mathbf{1 7}(2)$, pp. 450-457 (2013).

20. Li, W., Li, Q.N., and Jiang, W.S. "Parameter study on composite frames consisting of steel beams and reinforced concrete columns", Journal of Constructional Steel Research, 77, pp. 145-162 (2012).

21. ABAQUS User's Manual, Version 6.10-1, Pawtucket, RI: Hibbit, Karlsson \& Sorenson (2010).

22. ASTM A615/A615M-12, Standard Specification for Deformed and Plain Carbon-Steel Bars for Concrete Reinforcement (2012).

23. ASTM A572/A572M-12, Standard Specification for High-Strength Low-Alloy Columbium-Vanadium Structural Steel (2012).
24. Comité Euro-International du Béton (CEB-FIP Model Code 1990), International Recommendation for the Design and Construction of Concrete Structures, Thomas Telford, UK (1990).

\section{Biographies}

Nader K.A. Attari is an Associated Professor in the Department of Structural Engineering at Road, Housing, and Urban Development Research Center (BHRC). He completed his PhD in Structural Engineering at Sharif University of Technology in 2008. His favourite fields of research include innovative structural systems, seismic rehabilitation of exciting buildings, and nonlinear dynamics. Dr. Attari is the author of several journal and other papers and has contributed to some project reports.

Narges Azadvar is now a PhD candidate in the Department of Civil Engineering at West Tehran Branch of Islamic Azad University of Iran. She is working on RCS connections and strengthening of the concrete structures with composite materials like FRP and TRC. She completed her MSc degree working on cover plates in RCS connections under the Supervision of Dr. Attari.

Saeid Alizadeh completed his MSc in Structural Engineering in 2012 working on RCS connections under the Supervision of Dr. Attari. He worked for about three years in the industry before returning to the academic activities for the $\mathrm{PhD}$ degree. He is now a $\mathrm{PhD}$ candidate in Structural Engineering at University of Canterbury, New Zealand. His field of research is seismic response of diaphragms in steel frame structures. He has published a number of journal and conference papers and also contributed to a few technical reports. 